\title{
Telomerase activity in B-cell non-Hodgkin lymphomas is regulated by hTERT transcription and correlated with telomere-binding protein expression but uncoupled from proliferation
}

\author{
W Klapper,', M Krams', W Qian',2, D Janssen' and R Parwaresch' \\ 'Institute of Hematopathology and Lymph Node Registry Kiel, Niemannsweg II, 24105 Kiel, Germany; 'Department of Hematology, \\ First affiliated Hospital of Zhejiang University, Qianchun Road 79\#, Hangzhou 310003, China
}

\begin{abstract}
Telomere maintenance is a prerequisite for immortalisation, and in most malignant cells is carried out by telomerase, an enzyme that synthesises new telomeric repeats on the chromosome ends. In normal or reactive tissues with a high regenerative capacity, telomerase is regulated according to the telomere loss that occurs during proliferation. To evaluate the interaction of proliferation and telomerase activity in malignant lymphomas, we quantified telomerase expression in different non-Hodgkin lymphomas in comparison to normal or reactive lymph nodes. Surprisingly, the activity levels were the same in most of the lymphomas analysed as compared to reactive lymph nodes. Significantly higher activity was detected only in Burkitt's lymphoma. Telomerase activity correlated well with hTERT and c-myc expression, but was independent of proliferation. To evaluate interactions of telomere-binding protein expression on telomerase expression in non-Hodgkin lymphoma, the mRNA levels of TRFI, TRF2, tankyrase and hPifl were assessed by real-time RT-PCR. We demonstrate here that the magnitude of telomerase upregulation does not necessarily reflect the requirement of telomere compensation caused by proliferation. Telomerase regulation in non-Hodgkin lymphomas is therefore uncoupled from proliferative stimuli found in reactive lymphoid tissue. We suggest that the upregulation of specific telomere-binding proteins like TRF2 may contribute to telomere maintenance in malignant lymphoma.
\end{abstract}

British Journal of Cancer (2003) 89, 713-719. doi:I0.1038/sj.bjc.660। II2 www.bjcancer.com

(C) 2003 Cancer Research UK

Keywords: telomerase; non-Hodgkin lymphoma; TRFI; TRF2; hPifl; tankyrase

The telomeres of somatic cells shorten with each cell division due to the 'end-replication-problem'. Critically short telomeres induce an irreversible exit from the cell cycle, called senescence. Telomere loss is thus considered as a 'mitotic clock' that limits the proliferative capacity of somatic cells (Blackburn, 1991). Immortal cells such as stem cells and tumour cells express the enzyme telomerase that compensates telomere loss by adding new telomere repeats to the chromosomal ends. The expression of telomerase activity is therefore a crucial step towards an immortal phenotype during malignant transformation (Krupp et al, 2000). Telomerase activity can be detected in a variety of malignant cancers (Klingelhutz, 1997). Additional to 'immortal' cells, telomerase activity can also be detected in tissues with a high regenerative capacity such as lymphocytes, the basal layers of the skin epithelium or the endometrium (Buchkovich and Greider, 1996; Harle-Bachor and Boukamp, 1996; Bonatz et al, 1998). Telomerase activity in benign tissues is upregulated in telomerase-competent cells if proliferation occurs, for example, upon an in vitro (Belair et al, 1997) or in vivo stimulation (Bonatz et al, 1998).

Lymphocytes expand clonally during the response to antigenic challenge in the specific microenvironment of the germinal centre (GC). During this extensive cell expansion, telomerase activity is

*Correspondence: Dr W Klapper, E-mail: Wklapper@path.uni-kiel.de Received 3 October 2002; revised 12 March 2003; accepted 30 April 2003 upregulated in the proliferating compartment of the GC, the centroblasts (Weng et al, 1997). Unique to the GC reaction is the telomere elongation that occurs during telomerase activation. Centrocytes, GC cells that have already finished proliferative expansion, express lower levels of telomerase activity and still have longer telomeres than pre-GC naive B cells (Weng et al, 1997; Norrback et al, 2001). It is believed that the telomere elongation in the $\mathrm{GC}$ is a prerequisite for the lifelong ability of the immune system to expand a few or even a single antigen-specific B cell upon antigen encounter (Weng, 1999). Telomerase knockout mice do indeed show a reduced formation of GC in the late-generation mice, most likely caused by the inability of lymphocytes to restore their telomere length in the GC (Herrera et al, 2000).

Nearly $90 \%$ of non-Hodgkin lymphomas (NHLs) are B-cell NHL (B-NHL), of which the majority arise from GC cells or post-GC mature B cells, indicated by their immune phenotype as well as their mutated V-region of the immune globulin genes (Kuppers et al, 1999). Ongoing somatic hypermutation indicates the GC origin of the lymphoma for example, in follicular lymphoma (FL), $50 \%$ of the diffuse large B-cell lymphomas (DLBL) and Burkitt lymphomas. B-NHL of GC origin comprise over $70 \%$ of all B-NHL. A pre-GC origin is postulated for a subset of B-cell chronic lymphocytic leukaemia and for mantle cell lymphoma (MCL), cases that show unmutated Ig genes. Plasma cell myelomas on the other hand arise from post-GC cells (Kuppers et al, 1999). 
As (i) telomerase activation and telomere elongation occur in the GC under normal conditions, (ii) telomerase activity and telomere maintenance are a prerequisite for immortalisation and (iii) B-NHL predominantly arise from GC-cells, it is tempting to speculate that upregulation of telomerase and the associated events in the GC represent an 'Achilles' heel', which-if altered-leads to immortalisation of lymphoid cells. Telomerase activity can be detected in most cancers (Kim et al, 1994) as well as in lymphoma tissues (Norrback et al, 1996; Ely et al, 2000). The activity was reported to be positively correlated to the proliferation of the lymphoma (Ely et al, 2000).

This study was initiated to evaluate the mechanism and the extent of telomerase upregulation in lymphomas. The results may render an insight into the transformation process of NHL. In addition, we evaluated lymphomas as possible targets for telomerase inhibition drug therapy, which is discussed as a promising new approach in the treatment of several malignancies (Damm et al, 2001).

\section{MATERIAL AND METHODS}

\section{Samples}

From all lymphomas studied, fresh and paraffin-embedded samples as well as the relevant diagnostic cytogenetic information were available. Fresh specimens were obtained during surgery, overlayered with PBS, shock-frozen in liquid nitrogen and maintained at $-80^{\circ} \mathrm{C}$ until use. The lymphomas were diagnosed on the basis of Kiel and the recent WHO classification. The diagnoses were confirmed by the reference pathologists of the Lymph Node Registry Kiel on the basis of standard histopathology and appropriate immunohistochemical stainings using the alkaline phosphatase-anti-alkaline phosphatase (APAAP) technique with mouse monoclonal antibodies. Immunoreagents were all purchased from DAKO (Hamburg, Germany), except for anti-CD20, Ki-S2 (detection of repp86) and Ki-S5 (detection of Ki67), which had been generated at the Institute for Hematopathology, Kiel (Kreipe et al, 1993a; Heidebrecht et al, 1997).

\section{Telomerase activity assay (TRAP)}

Frozen samples were crushed with a sterile micropistill in ice-cold lysis buffer (CHAPS 0.5\%, $10 \mathrm{~mm}$ Tris- $\mathrm{HCl}$ (pH 7.5), $1 \mathrm{~mm} \mathrm{MgCl}_{2}$, $1 \mathrm{~mm}$ EGTA, $5 \mathrm{~mm} \beta$-mercaptoethanol, $0.01 \mathrm{~mm}$ AEBSF, $1 \mathrm{U}^{-1}$ RNAsin (Promega), 10\% glycerol). After incubation for $30 \mathrm{~min}$ on ice, the samples were centrifuged for $30 \mathrm{~min}$ at $4^{\circ} \mathrm{C}$ with $20.000 \mathrm{~g}$. The supernatant was snap-frozen in liquid nitrogen and stored at $-80^{\circ} \mathrm{C}$. The protein concentration of the extracts was determined by the Bradford assay.

The extracts were diluted appropriately and $200 \mathrm{ng}$ of protein (in $2 \mu \mathrm{l}$ ) was mixed with $48 \mu \mathrm{l}$ reaction mix containing $20 \mathrm{mM}$ Tris- $\mathrm{HCl}$ ( $\mathrm{pH}$ 8.0), $1 \mathrm{~mm}$ EGTA, 0.0005\% Tween 20, $1.5 \mathrm{mM} \mathrm{MgCl}_{2}, 63 \mathrm{~mm}$
$\mathrm{KCl}, 50 \mu \mathrm{M}$ each dNTP, $2 \mathrm{U}$ Taq, 0.001 amol ITAS, 10 pmol TSPrimer (5'-TAMRA labelled) and 10 pmol Cxext Primer (Krupp et al, 1997).

After a $30-\mathrm{min}$ incubation at $30^{\circ} \mathrm{C}$, the PCR conditions were as follows: $95^{\circ} \mathrm{C}$ for $3 \mathrm{~min}$ and 36 cycles of $95^{\circ} \mathrm{C}$ for $30 \mathrm{~s}, 50^{\circ} \mathrm{C}$ for $30 \mathrm{~s}$ and $72^{\circ} \mathrm{C}$ for $30 \mathrm{~s}$. The PCR products were analysed on an ABI prism 310 capillary electrophoresis unit as described (Krupp et al, 1997). The area under the first five telomerase peaks was added and divided by the area under the internal amplification standard (ITAS) peak. For semiquantitative measurement, a dilution series of Hl60 extract was analysed in parallel. Linear regression analysis of the telomerase peak/ITAS ratios of the dilution series was performed (GraphPad Prim). The experimental samples were expressed as corresponding nanograms of Hl60 protein.

\section{TaqMan RT - PCR and LightCycler RT - PCR}

Total RNA was extracted using the RNAzol Method. RNA (500 ng) was used for c-DNA synthesis using the First Strand Synthesis Kit (Invitrogen) and random priming. The resulting c-DNA was diluted $1: 1$ with TE buffer and $2 \mu \mathrm{l}$ was used in each TaqMan PCR. A 7700 Sequence Detection System (Applied Biosystems) was used. The primer and probes are shown in Table 1. A $50 \mu \mathrm{l} \mathrm{PCR} \mathrm{sample}$ contained reagents of the TaqMan PCR Core Reagents Kit (PE Biosystems) as recommended by the manufacturer, 10 pmol of each primer and $3 \mathrm{pmol}$ of the corresponding probe. For all targets, the PCR conditions were $95^{\circ} \mathrm{C}$ for $10 \mathrm{~min}$, followed by 40 cycles of $95^{\circ} \mathrm{C}$ for $10 \mathrm{~s}$ and $60^{\circ} \mathrm{C}$ for $1 \mathrm{~min}$. As a control and for the calculation of target amount in the experimental samples, DNA fragments of the target genes were amplified using the corresponding primer pairs and gel purified. A dilution series of these fragments was used in each TaqMan PCR in separate tubes and served as a standard curve (equivalent to $0.2,0.005,0.0125$, $0.003125,0.00078125$ and 0.0001953125 amol of pure DNA). After setting a threshold cycle, the TaqMan automatically calculates a linear regression of the standard curve of which the absolute amounts are known, and interpolates the values for the experimental samples. These are then expressed as attomol with respect to the standard curve. The value for the target gene was then divided by the value for $\beta$-actin that was generated in the same way. By using the DNA dilution series, a comparison of independent PCRs can be reliably performed.

For the detection of hTERT expression, a Lightcycler RT Kit (Roche) was used as recommended by the manufacturer. The primers and probe are designed to detect only biologically active full-length mRNA.

\section{Statistical analysis}

Analysis of variance (one-way ANOVA), correlation analysis and linear regression were calculated using GraphPad Prism version 3.00 for Windows, GraphPad Software, San Diego California, USA.

Table I Primers and TaqMan probes

\begin{tabular}{|c|c|c|}
\hline Gene & Primer & Probe \\
\hline TRFI & $\begin{array}{l}\text { F: TCCTCTgССТСТСТCTIgC } \\
\text { R: ggTTITTCCTgCTgCAATTC }\end{array}$ & CCAgTCTAACAgCTTGCCAgTTgAgAAC \\
\hline TRF2 & $\begin{array}{l}\text { F: CTgAgCTCACACCACTggAA } \\
\text { R: gCATCTTCTgCTggAAggTC }\end{array}$ & ACTgACAgAAgCAgTggTCgAACCAgT \\
\hline Tankyrase & $\begin{array}{l}\text { F: TgCATCCCAAACgTAAACAA-3' } \\
\text { R: ggTCAgAgCCgTAACCAgC- } 3^{\prime}\end{array}$ & ACCAAgggTgTCCAgTgCATTCATCT \\
\hline hPif & $\begin{array}{l}\text { F: gCCTCACCCACAAAgAgAAg-3' } \\
\text { R: CCTgAAAggAgggATgTCA }\end{array}$ & ACTggAgTAggCAggCAgTgTCCCCT \\
\hline c-myc & $\begin{array}{l}\text { F: ACCACCAgCAgCgACTCTgA } \\
\text { R: TCCAgCAgAAggTgATCCAgACT }\end{array}$ & ACCTTTgCCAggAgCCTgCCTC \\
\hline
\end{tabular}




\section{Immunohistochemistry}

Immunohistochemistry for proliferation was performed using monoclonal antibodies generated at the Institute for Hematopathology, Kiel. Detection of Ki-67 was elaborated with the antibody Ki-S5 (Kreipe et al, 1993b).The antibody Ki-S2 detects the antigen repp86, which is restrictedly expressed in the S-, G2and M-phase of the cell cycle (Heidebrecht et al, 1997). Staining with Ki-S2 was performed as described (Rudolph et al, 1998).

For calculation of the proliferative index, a representative but randomly chosen area of the lymphoma was examined with $\times 400$ magnification. In all, 1000 cells were counted and cells with positive nuclei were expressed as the percentage of all lymphoma cells. Ki-67 and repp86 positivity were evaluated in corresponding areas of the successive slides.

\section{RESULTS}

Telomerase activity levels are not correlated with proliferation in B-cell non-Hodgkin lymphomas

The proliferation index of B-NHL was evaluated by immunohistochemistry using two proliferation markers that have been characterised extensively elsewhere (Kreipe et al, 1993b; Heidebrecht et al, 1997). The antibody Ki-S2 recognizes the protein repp86 that is exclusively expressed during S-, G2- and M-phase of the cell cycle. In contrast, Ki-S5 recognizes the Ki-67 protein, which besides being expressed in S-, G2- and M-phase is also expressed in the G1-phase. The values for Ki-S2 positive cells are therefore lower than the value for Ki-S5 positive cells and reflect the number of actively cycling cells more precisely (Heidebrecht et al, 1997; Rudolph et al, 1998). The proliferation determined by Ki-S5 or Ki-S2 staining was significantly different between the lymphoma subgroups (one-way analysis of variance, $P<0.001$ for both antibodies) with low proliferation in the low-grade lymphomas (MCL, FL) and high proliferation in high-grade lymphomas (DLBC, Burkitt) (Figure 1A and B). The proliferation index in the group of MCL was very heterogeneous because four samples were blastoid variants of MCL. The proliferation of benign lymph nodes cannot be evaluated reliably because the proliferation is unequally distributed in the tissue. Using a semiquantitative assay, we evaluated telomerase activity in four different types of B-cell NHLs: mantle cell lymphoma, follicular lymphoma, diffuse large B-cell lymphoma and Burkitt lymphoma. Eight or seven samples of each lymphoma subtype were studied. As a control, eight lymph nodes with benign unspecific lymphadenitis were analysed. Telomerase activity could be detected in seven out of eight benign lymph nodes (range 1.6-49.0 ng). The lymphoma samples showed activity in 25 of 31 samples with a broad range of activity levels from 2.8 to $566 \mathrm{ng}$ of the corresponding HL60 control. Four lymphomas were telomerase negative (two FL and one DLBL). Two lymphomas demonstrated unspecific PCR inhibition indicated by a suppression of the internal amplification standard.

Interestingly, the levels of activity in mantle cell lymphoma (mean: 17.40; s.d.: 7.9), follicular lymphoma (mean: 5.40; s.d.: 3.60) and diffuse large B-cell lymphoma (mean: 15.80; s.d.: 16.10) did not differ significantly from the activity levels found in normal lymph nodes (mean: 17.40; s.d.: 15.80) (Figure 1C). Including the values for Burkitt's lymphoma (mean: 261.4; s.d.: 202.7) in the calculation, the data became statistically significantly different from a random distribution (one-way analysis of variance, $P<0.001)$. If blastoid variants of MCL were compared to normal MCL, no difference in telomerase activity was found (data not shown) although blastoid MCL did present with a significantly higher proliferation index (data not shown). These findings indicate that MCL, FL and DLBL lymphoma express telomerase activity levels that are undistinguishable from benign lymph nodes. Burkitt's lymphoma is the only B-NHL subtype analysed here,
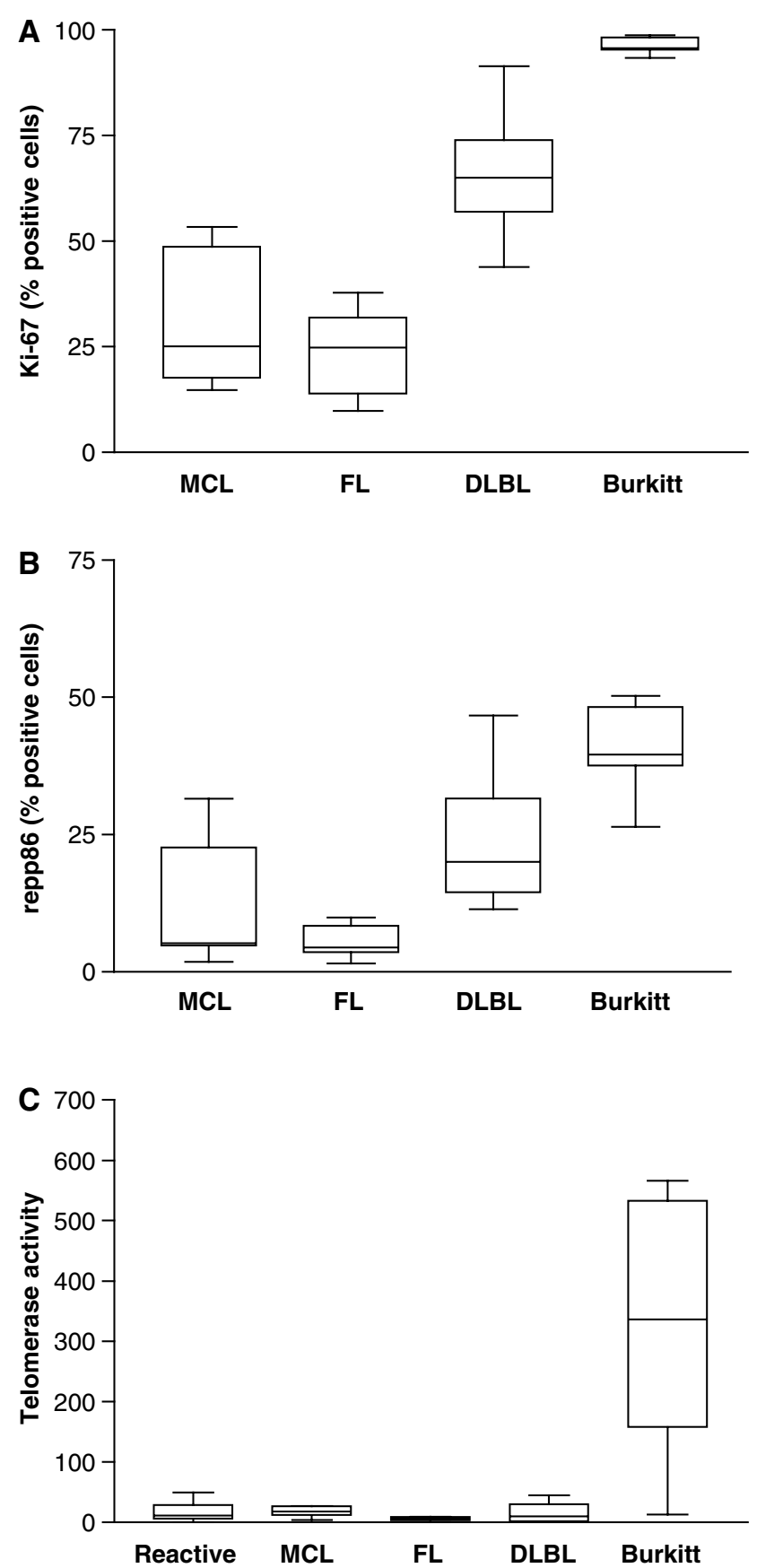

Figure I Proliferation measured by staining for the Ki67 (A) antigen and for repp86 (B). The percentage of positive cells was counted. In contrast to the repp86 antigen (detected by Ki-S2), the Ki-67 antigen is also expressed during GI-phase of the cell cycle. Thus, the values for Ki-67 are higher than for repp86 staining (one-way analysis of variance, $P<0.00$ I for both antibodies). The proliferative index cannot be determined for benign lymph nodes reliably because proliferation is unevenly distributed throughought the tissue. (C) Telomerase activity measured by a semiquantitative TRAP. The activity is expressed as nanograms of an HL60 control cell line. In total, $200 \mathrm{ng}$ experimental sample was used in each assay. No significant differences were found between benign lymph nodes (benign), MCL, FL and DLBL. High activity was measured in Burkitt's lymphoma (Burkitt) (oneway analysis of variance, $P<0.00 \mathrm{I}$ ).

which expresses significantly higher levels than benign lymph nodes. Although there are obvious differences in the percentage of proliferation cells between low-grade lymphomas (MCL, FL) and DLBL, telomerase activity levels are similar (Figure 1C). 


\section{Telomerase activity correlates with hTERT and} c-myc expression

To explain the observed differences in telomerase activity between Burkitt's lymphoma and all other lymphomas analysed here, we performed a real-time RT-PCR for the catalytic subunit of telomerase hTERT. In most tumours and benign tissues studied so far, hTERT expression correlates well with the expression of telomerase activity (Figure 2A). HTERT levels did show a similar expression pattern like telomerase activity (one-way analysis of variance: $P<0.001$, correlation: $P=0.025$ ). The low levels of activity in MCL, FL and DLBL are thus most likely due to low
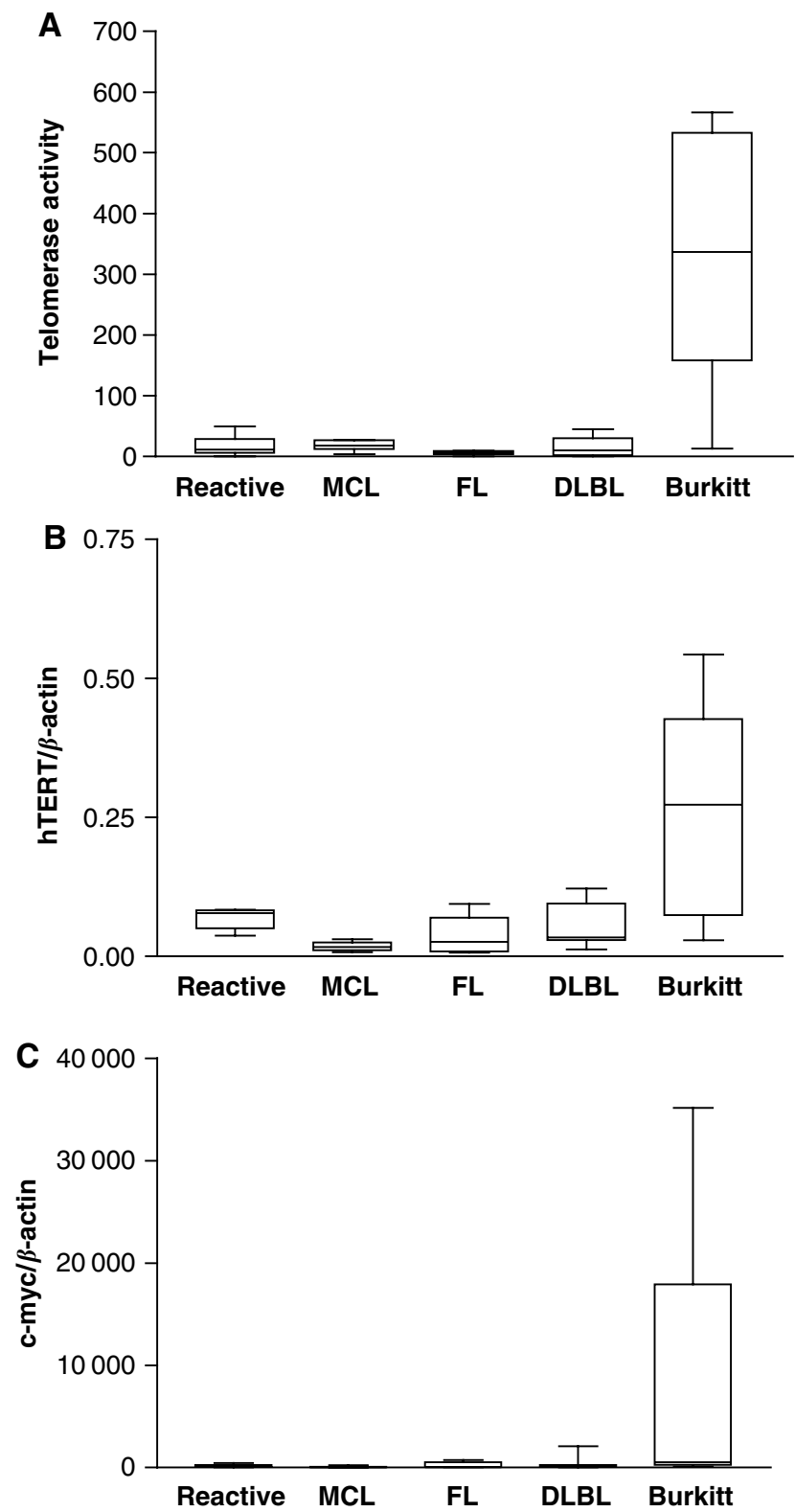

Figure 2 (A) Telomerase activity measured by a semiquantitative TRAP as shown in Figure IC. (B) HTERT mRNA expression detected by realtime RT-PCR using a LightCycler Assay. The expression level of hTERT in the lymphomas is similar to telomerase activity (one-way analysis of variance: $P<0.0018$, correlation: $P=0.0025, \quad r=0.9826$ ). (C) C-myc expression detected with real-time RT-PCR using a TaqMan assay. Cmyc is strongly overexpressed in Burkitt's lymphoma, which carry the $\mathrm{t}(8 ; \mid 4)$ translocation (one-way analysis of variance: $P=0.0079$ ).
hTERT expression. Burkitt's lymphoma did show high hTERT expression accordingly (Figure 2A).

One of the best characterised transcription factors of the hTERT gene is c-myc (Wang et al, 1998; Greenberg et al, 1999; Kyo et al, 2000; Xu et al, 2001). We performed a real-time RT-PCR to determine the c-myc expression in the NHL samples. As expected, the highest c-myc expression was found in Burkitt's lymphoma (Figure 2B). The $\mathrm{t}(8 ; 14)$ translocation that is found in almost all Burkitt's lymphoma translocates the $c-m y c$ gene under the influence of the immunoglobulin heavy chain promoter and thus induces a c-myc overexpression (Kuppers et al, 1999). Altogether, the $c-m y c$ expression shows a similar distribution compared to telomerase activity and hTERT expression: high levels found in Burkitt's lymphoma and lower levels in benign lymph nodes, MCL, FL and DLBL again with no relevant differences among benign lymphnodes, MCL, FL and DLBL (one-way analysis of variance: $P=0.0079$, Figure 2C). These data suggest that the high telomerase activity found in Burkitt's lymphoma is probably caused by hTERT overexpression. HTERT upregulation might be an effect of the high c- $m y c$ levels. Similar levels of telomerase activity or hTERT in MCL and FL indicate that the regulation of telomerase is independent of a GC phenotype of the lymphoma.

\section{Differential expression of telomere-binding proteins in B-cell NHLs}

If telomerase activity is needed for telomere length maintenance in immortal cells, the requirement for such an activity should be higher, the more and faster the cell divisions are carried out. As no differences in telomerase activity and hTERT expression could be detected in benign lymph nodes, MCL, FL and DLBL, although high variations in the proliferative index were present, we speculated that other mechanisms might contribute to telomere maintenance in these lymphomas. A number of specific telomerebinding proteins have been characterised so far. Among these are negative regulators of telomere length such as TRF1 and TRF2 (Smogorzewska et al, 2000), as well as positive regulators like tankyrase (Smith and De Lange, 2000). The helicase hPifl has been described as a telomerase inhibitor (Zhou et al, 2000). We studied the expression levels of TRF1, TRF2 tankyrase and hPif1 in B-cell NHL by TaqMan RT - PCR (Figure 3). TRF1 as well as tankyrase, an inhibitor of TRF1, did not show significant differences in their expression levels between all tissues examined, including Burkitt's lymphoma (one-way analysis of variance, $P=0.433$ for TRF1 and $P=0.508$ for hPif1). TRF2 and hPif1 expressions were highest in Burkitt's lymphoma and showed only minor differences between benign lymph nodes, MCL, FL and DLBL (one-way analysis of variance: $P=0.0239$ for TRF2, $P=0.0105$ for hPif1). The level of TRF2 as well as hPif1 correlated positively with telomerase activity (correlation: $P=0.0455$ and $r=0.8856$ for TRF2 and $P=0.0128$ and $r=0.9514$ for hPif1, respectively). Taken together, these data suggest a differential expression of TRF2 and hPif1 in NHL with an upregulation in Burkitt's lymphoma. Low levels without significant differences were detected in benign lymph nodes, MCL, FL and DLBL.

\section{DISCUSSION}

Telomeres are specialised structures at the chromosome ends that (i) protect the ends from end-to-end fusion, (ii) impede the double-strand break machinery to recognise the ends as breaks, (iii) mediate correct pairing of the telomeres during mitosis and meiosis and (iv) function as a buffer zone for the loss of terminal DNA that occurs with each cell division (Pardue and Debaryshe, 1999). To circumvent telomere shortening, immortal cells, like tumour cells or stem cells, express telomerase activity by upregulating the expression of the catalytic subunit of the enzyme, 

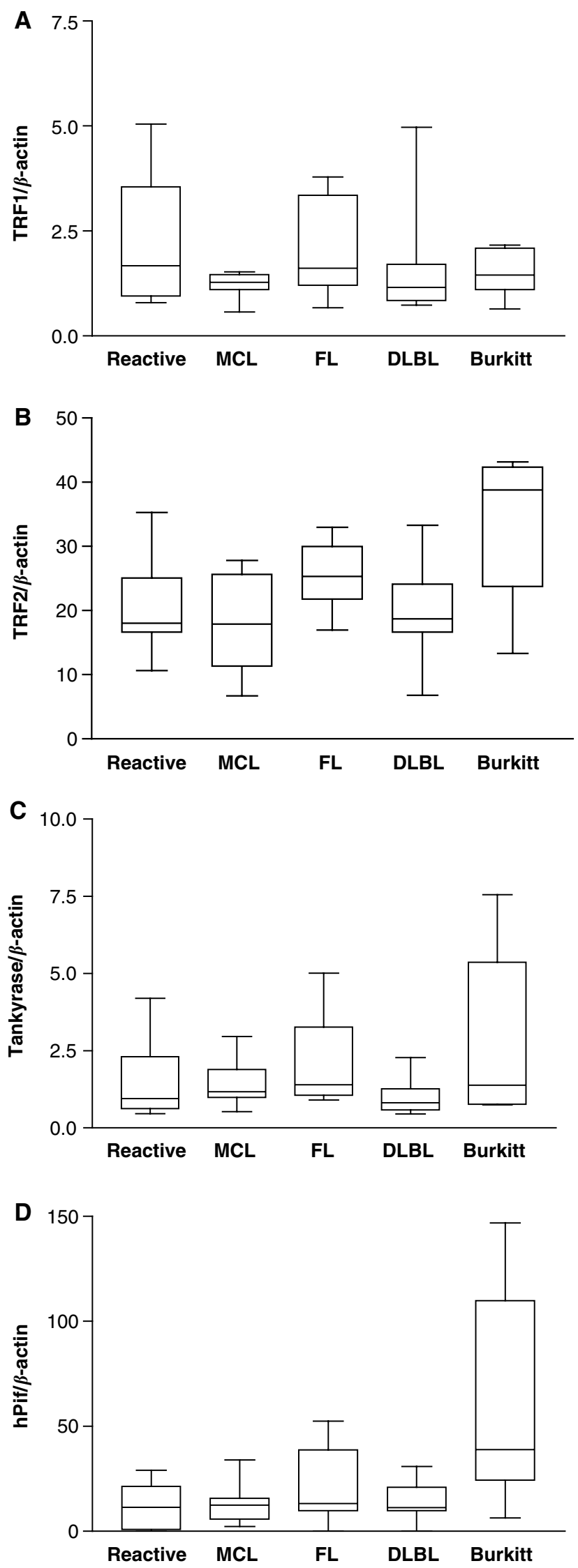

hTERT. As telomerase upregulation is a feature of lymphocyte expansion during the GC reaction and B-NHL frequently arise from GC cells, we studied telomerase activity and hTERT expression in B-NHL.

Several publications report on telomerase activity in B-cell NHLs. In these studies, increased telomerase activity was found in B-NHL compared to reactive lymph nodes. Furthermore, a positive correlation of telomerase activity with the rate of proliferation in the B-NHL was found (Norrback et al, 1996; Brousset et al, 1997; Ely et al, 2000; Remes et al, 2000; Lin et al, 2001). In contrast to these studies, we did not find an upregulation of telomerase activity in most of the NHL compared to reactive lymph node tissue (Norrback et al, 1996). The only NHL that showed significantly higher telomerase activity was Burkitt's lymphoma, which expressed approximately $17 \times$ the activity found in reactive lymph nodes, MCL, FL and DLBL.

To validate these data, we performed real-time RT-PCR analysis of the catalytic subunit of telomerase hTERT, because in most tissues and tumours studied so far, the presence and quantity of full-length hTERT mRNA correlate well with telomerase activity (Ulaner et al, 1998; Krams et al, 2001). Full-length hTERT expression measured by real-time RT-PCR also correlated with the levels of telomerase activity in our samples. Furthermore, a known important transcription factor for the hTERT gene, c-myc, did show a similar expression pattern like hTERT and telomerase activity, respectively. We conclude that the upregulation of telomerase activity found in Burkitt's lymphoma is caused by a transcriptional upregualtion of hTERT, which is most likely caused by c-myc overexpression. The GC phenotype of a B-NHL apparently does not necessarily evoke and is probably independent of the level of telomerase activity and hTERT expression. MCL express the same levels like DLBL, and FL express even at the lowest levels. As within the group of lymphomas with constantly low telomerase activity (MCL, FL, DLBL) the proliferation varied substantially, a positive correlation of telomerase activity or hTERT expression with proliferation cannot be found. Thus, in contrast to reactive lymphocytes and the GC reaction, telomerase activity and hTERT expression in malignant lymphomas seem to be uncoupled from rates of proliferation (Buchkovich and Greider, 1996; Weng et al, 1996, 1997).

The discrepancies in our findings to the current literature (Norrback et al, 1996; Ely et al, 2000) might be explained by the use of a nonquantitative telomerase activity assay and the lack of data on quantitative RT - PCR for hTERT in earlier studies. Our telomerase activity assay is capable of detecting reproducibly small differences and shows a broad linear range (Klapper et al, 1998). Quantitative real-time RT-PCR analysis of hTERT strongly supports our results on telomerase activity.

Theoretically, the need for telomerase activity to maintain telomere length in an immortal cell clone is positively correlated to the number of cell divisions that are carried out. In other words, a high number of proliferating cells in a tumour would require relatively high telomerase activity compared to tumours with low proliferation. As the telomere length in most malignancies, including B-NHL, is shorter than in the corresponding normal tissue, a further shortening due to insufficient telomerase activity would lead to cell death (Remes et al, 2000). Thus, maintenance of telomere integrity seems even more critical for malignant than for normal cells. The existence of an alternative telomerase-independent mechanism for telomere length preservation (ALT) in the lymphomas examined here cannot be ruled out completely. As no

Figure 3 Telomere-binding protein expression detected by real-time RT-PCR using TaqMan assays. The expression is indicated relative to $\beta$ actin endogenous control: (A) TRFI (one-way analysis of variance: $P=0.433$ ); (B) TRF2 (one-way analysis of variance: $P=0.0239$ ), $(\mathbf{C})$ tankyrase (one-way analysis of variance: $P=0.508$ ), (D) hPifl (one-way analysis of variance: $P=0.0105)$. 
specific test for the ALT exists that can be applied to tissue samples, so far only indirect evidence can be obtained from the telomere length pattern (Bryan et al, 1995; Dunham et al, 2000). However, studies of telomere length pattern in B-NHL suggest that most of the lymphomas have telomeres that point to a telomerase-dependent pathway of telomere maintenance (Remes et al, 2000).

The lack of correlation in telomerase activity and proliferation in B-NHL found in this study, led us to examine telomere-binding protein expression. A downregulation of negative telomere length regulators in lymphomas with relatively high proliferation and relatively low telomerase activity (e.g. DLBL) could balance telomere loss and synthesis. Some of these proteins have been shown to be negative regulators of telomere length in the presence of telomerase activity (e.g. TRF1, hPif1 and to some extent TRF2) (Smogorzewska et al, 2000; Zhou et al, 2000). Others like tankyrase positively influence telomere length (Smith and De Lange, 2000). The effect of these proteins seems mainly to be mediated by altering the access of telomerase to its substrate, the telomere (van Steensel and De Lange, 1997; Smogorzewska et al, 2000). We found similar levels of TRF1 and tankyrase expression in all lymphomas studied. Interestingly, similar low levels of TRF2 and hPif1 were found in the samples with low telomerase activity (reactive lymph nodes, MCL, FL, DLBL), while Burkitt's lymphoma expressed significantly higher levels. HPif1 is a helicase that directly associates with telomeric DNA (Zhou et al, 2000). Overexpression of Piflp in yeast results in telomere shortening by inhibiting telomerase-mediated telomere lengthening (Zhou et al, 2000). TRF2, on the other hand, mainly functions in telomere endprotection by mediating telomere folding to t-loops (van Steensel et al, 1998; Griffith et al, 1999; Stansel et al, 2001) but if overexpressed, TRF2 also negatively influences telomere length (Smogorzewska et al, 2000). Interestingly, overexpressing TRF2 in human primary cells protects critically shortened telomeres and delays senescence (Karlseder et al, 2002). This is the first work that determines telomerase expression and such a broad range of telomere-binding protein expression in a quantitative manner in malignant and reactive tissue. The upregulation of telomerase activity in parallel with an upregulation of proteins that inhibit telomerase-mediated telomere lengthening indicate that the importance of high telomerase levels for maintenance of telomere length might be overestimated. Telomerase upregulation might just be a side effect of the high c-myc levels found in Burkitt's lymphoma, which again might cause high hTERT levels as shown

\section{REFERENCES}

Belair CD, Yeager TR, Lopez PM, Reznikoff CA (1997) Telomerase activity: a biomarker of cell proliferation, not malignant transformation. Proc Natl Acad Sci USA 94: 13677-13682

Blackburn EH (1991) Structure and function of telomeres. Nature 350: $569-573$

Bonatz G, Klapper W, Barthe A, Heidorn K, Jonat W, Krupp G, Parwaresch $\mathrm{R}$ (1998) Analysis of telomerase expression and proliferative activity in the different layers of cyclic endometrium. Biochem Biophys Res Commun 253: 214-221

Brousset P, al Saati T, Chaouche N, Zenou RC, Schlaifer D, Chittal S, Delsol G (1997) Telomerase activity in reactive and neoplastic lymphoid tissues: infrequent detection of activity in Hodgkin's disease. Blood 89: 26-31

Bryan TM, Englezou A, Gupta J, Bacchetti S, Reddel RR (1995) Telomere elongation in immortal human cells without detectable telomerase activity. EMBO J 14: $4240-4248$

Buchkovich KJ, Greider CW (1996) Telomerase regulation during entry into the cell cycle in normal human T cells. Mol Biol Cell 7: 1443-1454

Corey DR (2002) Telomerase inhibition, oligonucleotides, and clinical trials. Oncogene 21: $631-637$

Damm K, Hemmann U, Garin-Chesa P, Hauel N, Kauffmann I, Priepke H, Niestroj C, Daiber C, Enenkel B, Guilliard B, Lauritsch I, Muller E, here. On the other hand, stabilisation of shorter tumour telomeres might need higher levels of telomere-binding protein expression. Upregulation of proteins that delay telomere damage signals like TRF2 might play a key role in this process. Further studies of tumours characterised quantitatively for telomerase activity, telomere-binding protein expression and additionally telomere length will provide more insight into the interaction of these three components in the stabilisation of telomeres in malignant and benign cells.

Telomerase inhibition is discussed as a promising approach for treating a variety of malignant tumours. Two main prerequisites should match if a tumour is suitable for telomerase-inhibition therapy: (i) Telomerase activity must be detectable and must therefore be the main mechanism of telomere maintenance. We show here that the level of expression does not necessarily reflect the requirement for telomere maintenance due to proliferation. Thus, tumours with low telomerase activity also can be sensitive to telomerase inhibition if (ii) telomeres of the tumour are significantly shorter than telomeres of normal tissue, especially of stem cells. In this case, inhibition of telomerase activity would shorten tumour telomeres faster to a critical length than in normal tissue and would therefore induce cell death selectively in tumour cells (Remes et al, 2000). Adding a new layer of complexity, we demonstrate, that telomere-binding protein expression varies in NHLs. We propose that besides telomerase activity and telomere length, telomere-binding protein expression also might influence the efficiency of telomerase-inhibition therapy. High levels of TRF2 have been shown to prevent or delay the signalling of a critically shortened telomere to induce senescence (Karlseder et al, 2002). Therefore, tumours that overexpress TRF2-like Burkitt's lymphoma, might be more resistant to telomerase-inhibition therapy. This hypothesis has to be tested in cell culture models using the currently available specific telomerase inhibitors in cell lines that overexpress, for example, TRF2 or hPif1 (Damm et al, 2001; Corey, 2002).

\section{ACKNOWLEDGEMENTS}

We thank Oliviera Batic for technical assistance. This work was supported in part by the European Mantle Cell Lymphoma Study Group and by the Kinderkrebsinitiative, Buchholz-HolmSeppensen.
Pascolo E, Sauter G, Pantic M, Martens UM, Wenz C, Lingner J, Kraut N, Rettig WJ, Schnapp A (2001) A highly selective telomerase inhibitor limiting human cancer cell proliferation. EMBO J 20: 6958-6968

Dunham MA, Neumann AA, Fasching CL, Reddel RR (2000) Telomere maintenance by recombination in human cells. Nat Genet 26: 447-450

Ely SA, Chadburn A, Dayton CM, Cesarman E, Knowles DM (2000) Telomerase activity in B-cell non-Hodgkin lymphoma. Cancer 89: $445-452$

Greenberg RA, O'Hagan RC, Deng H, Xiao Q, Hann SR, Adams RR, Lichtsteiner S, Chin L, Morin GB, DePinho RA (1999) Telomerase reverse transcriptase gene is a direct target of c-Myc but is not functionally equivalent in cellular transformation. Oncogene 18: 1219-1226

Griffith JD, Comeau L, Rosenfield S, Stansel RM, Bianchi A, Moss H, De Lange T (1999) Mammalian telomeres end in a large duplex loop. Cell 97: $503-514$

Harle-Bachor C, Boukamp P (1996) Telomerase activity in the regenerative basal layer of the epidermis in human skin and in immortal and carcinoma-derived skin keratinocytes. Proc Natl Acad Sci USA 93: $6476-6481$

Heidebrecht HJ, Buck F, Steinmann J, Sprenger R, Wacker HH, Parwaresch $R$ (1997) p100: a novel proliferation-associated nuclear protein 
specifically restricted to cell cycle phases S, G2, and M. Blood 90: $226-233$

Herrera E, Martinez A, Blasco MA (2000) Impaired germinal center reaction in mice with short telomeres. EMBO J 19: $472-481$

Karlseder J, Smogorzewska A, De Lange T (2002) Senescence induced by altered telomere state, not telomere loss. Science 295: 2446-2449

Kim NW, Piatyszek MA, Prowse KR, Harley CB, West MD, Ho PL, Coviello GM, Wright WE, Weinrich SL, Shay JW (1994) Specific association of human telomerase activity with immortal cells and cancer. Science 266: $2011-2015$

Klapper W, Singh KK, Heidorn K, Parwaresch R, Krupp G (1998) Regulation of telomerase activity in quiescent immortalized human cells. Biochim Biophys Acta 1442: $120-126$

Klingelhutz AJ (1997) Telomerase activation and cancer. J Mol Med 75: $45-49$

Krams M, Claviez A, Heidorn K, Krupp G, Parwaresch R, Harms D, Rudolph P (2001) Regulation of telomerase activity by alternate splicing of human telomerase reverse transcriptase mRNA in a subset of neuroblastomas. Am J Pathol 159: 1925-1932

Kreipe H, Heidebrecht HJ, Hansen S, Rohlk W, Kubbies M, Wacker HH, Tiemann M, Radzun HJ, Parwaresch R (1993a) A new proliferationassociated nuclear antigen detectable in paraffin- embedded tissues by the monoclonal antibody Ki-S1. Am J Pathol 142: 3-9

Kreipe H, Wacker HH, Heidebrecht HJ, Haas K, Hauberg M, Tiemann M, Parwaresch R (1993b) Determination of the growth fraction in nonHodgkin's lymphomas by monoclonal antibody Ki-S5 directed against a formalin-resistant epitope of the Ki-67 antigen. Am J Pathol 142: 1689 - 1694

Krupp G, Klapper W, Parwaresch R (2000) Cell proliferation, carcinogenesis and diverse mechanisms of telomerase regulation. Cell Mol Life Sci 57: $464-486$

Krupp G, Kuhne K, Tamm S, Klapper W, Heidorn K, Rott A, Parwaresch R (1997) Molecular basis of artifacts in the detection of telomerase activity and a modified primer for a more robust 'TRAP' assay. Nucleic Acids Res 25: $919-921$

Kuppers R, Klein U, Hansmann ML, Rajewsky K (1999) Cellular origin of human B-cell lymphomas. N Engl J Med 341: 1520-1529

Kyo S, Takakura M, Taira T, Kanaya T, Itoh H, Yutsudo M, Ariga H, Inoue M (2000) Sp1 cooperates with c-Myc to activate transcription of the human telomerase reverse transcriptase gene (hTERT). Nucleic Acids Res 28: $669-677$

Lin Z, Lim S, Viani MA, Sapp M, Lim MS (2001) Down-regulation of telomerase activity in malignant lymphomas by radiation and chemotherapeutic agents. Am J Pathol 159: $711-719$

Norrback KF, Dahlenborg K, Carlsson R, Roos G (1996) Telomerase activation in normal B lymphocytes and non-Hodgkin's lymphomas. Blood 88: $222-229$
Norrback KF, Hultdin M, Dahlenborg K, Osterman P, Carlsson R, Roos G (2001) Telomerase regulation and telomere dynamics in germinal centers. Eur J Haematol 67: 309-317

Pardue ML, Debaryshe PG (1999) Telomeres and telomerase: more than the end of the line. Chromosoma 108: $73-82$

Remes K, Norrback KF, Rosenquist R, Mehle C, Lindh J, Roos G (2000) Telomere length and telomerase activity in malignant lymphomas at diagnosis and relapse. Br J Cancer 82: 601-607

Rudolph P, Knuchel R, Endl E, Heidebrecht HJ, Hofstader F, Parwaresch R (1998) The immunohistochemical marker Ki-S2: cell cycle kinetics and tissue distribution of a novel proliferation-specific antigen. Mod Pathol 11: $450-456$

Smith S, De Lange T (2000) Tankyrase promotes telomere elongation in human cells. Curr Biol 10: 1299 - 1302

Smogorzewska A, van Steensel B, Bianchi A, Oelmann S, Schaefer MR, Schnapp G, De Lange T (2000) Control of human telomere length by TRF1 and TRF2. Mol Cell Biol 20: 1659-1668

Stansel RM, De Lange T, Griffith JD (2001) T-loop assembly in vitro involves binding of TRF2 near the $3^{\prime}$ telomeric overhang. EMBO J 20: $5532-5540$

Ulaner GA, Hu JF, Vu TH, Giudice LC, Hoffman AR (1998) Telomerase activity in human development is regulated by human telomerase reverse transcriptase (hTERT) transcription and by alternate splicing of hTERT transcripts. Cancer Res 58: $4168-4172$

van Steensel B, De Lange T (1997) Control of telomere length by the human telomeric protein TRF1. Nature 385: $740-743$

van Steensel B, Smogorzewska A, De Lange T (1998) TRF2 protects human telomeres from end-to-end fusions. Cell 92: 401-413

Wang J, Xie LY, Allan S, Beach D, Hannon GJ (1998) Myc activates telomerase. Genes Dev 12: 1769-1774

Weng N (1999) Telomeres, telomerase, and lymphocyte replicative life span. Clin Immunol 92: 1 -2

Weng NP, Granger L, Hodes RJ (1997) Telomere lengthening and telomerase activation during human B cell differentiation. Proc Natl Acad Sci USA 94: 10827 - 10832

Weng NP, Levine BL, June CH, Hodes RJ (1996) Regulated expression of telomerase activity in human T lymphocyte development and activation. J Exp Med 183: $2471-2479$

Xu D, Popov N, Hou M, Wang Q, Bjorkholm M, Gruber A, Menkel AR, Henriksson M (2001) Switch from Myc/Max to Mad1/Max binding and decrease in histone acetylation at the telomerase reverse transcriptase promoter during differentiation of HL60 cells. Proc Natl Acad Sci USA 98: $3826-3831$

Zhou J, Monson EK, Teng S, Schulz VP, Zakian VA (2000) Pif1p helicase, a catalytic inhibitor of telomerase in yeast. Science 289: $771-774$ 